\title{
Cardioprotective Effects of Insect Apis Melifera Based Complementary Foods Using an In-Vivo White Albino (BALB/c) Mice
}

Shewangzaw Addisu Mekuria ( $\nabla$ shewakibr12@gmail.com )

JKUAT: Jomo Kenyatta University of Agriculture and Technology https://orcid.org/0000-0001-90203837

John Kinyuru

Jomo Kenyatta University of Agriculture and Technology

Beatrice Kiage Mokua

Jomo Kenyatta University of Agriculture and Technology

Mesfin Wogayehu Tenagashaw

Bahir Dar University

\section{Research Article}

Keywords: Atherogenic Indices, Cardiovascular disease, Complementary Foods, Diet, Lipid, Mice

Posted Date: September 3rd, 2021

DOl: https://doi.org/10.21203/rs.3.rs-850470/v1

License: (9) This work is licensed under a Creative Commons Attribution 4.0 International License.

Read Full License 


\section{Abstract}

Background-Cardiovascular disease is the cause of one-third of deaths worldwide and this status is likely to progress because of increasing CVD's risk factors like intake of cholesterol and saturated fat. There is no clear evidence that a poor diet in childhood is associated with CVD risk factor development and adverse vascular health in adulthood. Hence, it is important to look at the effects of complementary foods. Therefore, this study assessed the cardioprotective effects of insect bee larvae (Apis Melifera) based complementary foods in young white albino mice

Methods- The experiment was conducted using a randomized control design. Data were analyzed using IBM SPSS version 23. A total of Seventy-five male white Albino mice were randomly assigned to five diets in triplicate. The diets were Diet 1 = Casein diet; Diet 2= (57\% Maize, 29\% Teff, $14 \%$ Soybean); Diet 3= (58\% Maize, 29\% Teff, 13\% Bee larvae); Diet 4=Commercial wean mix; and Diet 5= Basal diet alone. The study was conducted for 28 days with seven days of acclimatization. Diet and water were given ad libitum. The mice blood sample was collected from a cardiac puncture. Lipid profiles of TC, TG, HDL-C and LDL-C evaluations were analyzed using automated pentra C400 made in France.

Results- The results showed a statistically significant difference $(P<0.001)$ of lipid profiles between treatments. Biochemical $(\mathrm{mg} / \mathrm{dl})$ parameters showed Diet 3 were recorded high TG (167.79) and HDL-C (67.18) and low in LDL-C (71.73). Atherogenic indices of Diet 3 were low in CRI-I (1.84), CRI-II (1.07), and $A C$ (0.84). LDL-C levels were positively correlated with all atherogenic indices, while HDL-C levels were negatively correlated. Atherogenicity indices showed significant positive associations $(P<0.001)$ with one another; CRI-I vs CRI-II ( $r=0.919)$, CRI-I vs AC $(r=1)$, CRI-II vs AC $(r=0.919)$. Nevertheless, AIP was positively correlated with CRI-I, CRI-II, and AC, however, this was not statistically significant $(P>0.05)$.

Conclusions- Intake of insect bee larvae-based diet could have the potential to protect from atherosclerotic cardiovascular disease in infants and young children. However, further studies on the adverse effects of the developed complementary foods on clinical and histopathological trials should be conducted.

\section{Background}

Nowadays, worldwide cardiovascular disease (CVD) is the leading cause of morbidity and mortality (Weber \& Noels, 2011; WHO, 2018), representing 30\% of all deaths worldwide (Casas et al., 2018). The development of coronary heart disease (CHD) is a common disease caused by increased intake of cholesterol and saturated fat, decreased intake of polyunsaturated fatty acids (PUFAs), and increased obesity (Kuller, 2006). However, the associations of total cholesterol and the relative amount of cholesterol in individual lipoprotein classes to CHD are complicated (Castelli et al., 1983).

The internalization of lipids, especially low-density lipoproteins (LDL), in the intima contributes to the early stages of atherosclerosis, which leads to endothelial dysfunction (Mehta \& Malik, 2006).

Atherosclerosis is an inflammatory disease that contributes to the major incidence and mortality of CVD 
(Casas et al., 2018). In the process of atherosclerosis, lipids accumulate on the walls of blood vessels and cause inflammatory reactions, thereby stimulating the development of atherosclerosis (Weber \& Noels, 2011). For early atherosclerosis and CVD lipid profile of (dyslipidemia) is a major risk factor (AI Shawaf et al., 2020; Kanthe et al., 2012). Dyslipidemia is defined as a rise in plasma lipid concentrations (triglycerides (TG) and total cholesterol (TC), as well as their blood-carrying lipoproteins of high density lipoproteins cholesterol (HDL-C), and LDL-C (U. Nwagha et al., 2010). The significance of dyslipidemia is based on the triad of an increase in LDL and triglycerides ( $\mathrm{Ng}$ et al., 1992) particles and a decrease in HDL levels (Rached et al., 2014). Lowering LDL-C levels is well established as an intervention for reducing CVDs (Rached et al., 2014).

So, to reduce the risk efficient and effective therapies are highly needed (Soppert et al., 2020; Weber \& Noels, 2011). Natural and dietary bioactive compounds (Mozaffarian \& Ludwig, 2010), and a healthy lifestyle (Berciano \& Ordovás, 2014; Sharifi-Rad et al., 2020) are believed to prevent coronary artery disease (Sharifi-Rad et al., 2020). Also, dietary Saturated Fatty Acids (SFA) restriction has long been a pillar of CVD dietary treatment (Siri-Tarino \& Krauss, 2016). As a result, identifying and classifying nutrients and foods that help prevent CVD is crucial (Lacroix et al., 2017).

Diet has a significant influence on the progress and anticipation of CVD (Berciano \& Ordovás, 2014; Briggs et al., 2017). The main lifestyle strategy for lowering CVD risk is to eat a diverse diet, with existing recommendations emphasizing lowering LDL-C by limiting SFA consumption (Siri-Tarino \& Krauss, 2016). Saturated and trans fatty acids boost overall and LDL-C, which is both linked to an increased risk of CHD. As a result, the use of saturated and trans fatty acids should be restricted. Natural health products are becoming more common, and they can help sustain and avoid CVDs (Sharifi-Rad et al., 2020). SFA and monounsaturated fatty acids (MUFA) (Chane et al., 2018) have similar compositions across life stages and diets.

Honeybees at all stages of development are an excellent food source due to their high protein content and optimal compositions of saturated and mono-unsaturated fatty acids (Finke, 2005; Ghosh et al., 2016). Palmitic, stearic, and oleic acids are the dominant fatty acids in all stages of bee broad (Ghosh et al., 2016; Haber et al., 2019). A high level of SFA is related to atherosclerosis and heart failure, however, some of them, such as stearic acid, which is found in the bee larvae, help to lower LDL cholesterol levels (Mensink, 2005). Therefore, the inclusion of bee larvae with others food ingredients can be used to develop complementary foods (CFs) that are nutritionally adequate and healthy (Shewangzaw et al., 2021). The raised levels of TC, LDL-C, and TG, as well as HDL-C, have traditionally been associated with atherosclerosis. Currently, the Atherogenic Index of Plasma (AIP) (Wu et al., 2018), Castelli's risk indices I (CRI-I) and II (CRI-II), and the Atherogenic Coefficient (AC) parameters are used for a better prognosis in cases of CVDs (Afrifa et al., 2019; Castelli et al., 1983).

There is now clear evidence that a poor diet in childhood is associated with CVD risk factor development and adverse vascular health in adulthood. Thus, a higher-quality diet during childhood is associated with a lower incidence of CVD risk factors and better vascular health in adulthood (Briggs et al., 2017). For 
both nutritional and developmental reasons, CF is needed when breast milk (or infant formula) alone is no longer available (Przyrembel, 2012). Since infants readily adopt new foods and easily learn to like them, the starting of complementary feeding is a critical time for the formation of food preferences (Chambers, 2016). Additionally, interest in the quality of dietary lipid supply in early childhood as a major determinant of growth, infant development, and long-term health is presently growing (Uauy \& Castillo, 2003). Dietary lipids have an early impact on cholesterol synthesis and are linked to cardiovascular morbidity and mortality later in life (Uauy \& Castillo, 2003). Malnourished children with congenital heart disease are common (Vieira et al., 2007). Though, there is no indication that the age at which CFs are added affects the likelihood of CHD (Przyrembel, 2012). Some evidence that growth rates during some stages of childhood and adolescence affect risk. The low birth weight, combined with a rapid rise in body mass index in early childhood is linked to the highest risk (Prentice \& Williams, 2011). However, there is no research output on the association of insect-based bee larvae-developed CFs with cardioprotective or cardiovascular disease on infants and young children using an in-vivo mice model on the serum lipid profiles. Therefore, the objective of the present study was to evaluate the cardioprotective effects of insect bee larvae (Apis Melifera) based CFs in young white albino (BALB/c) mice.

\section{Materials And Methods}

\subsection{Experimental Animals}

The ethical committee of the College of Veterinary Medicine and Animal Sciences, University of Gondar, Ethiopia, approved the experimental animal care and experimentation in this study, which followed the National Institutes of Health $(\mathrm{NIH})$ Guide for Care and Use of Laboratory Animals and the EEC directive of 1986 (86/609/EEC). An average of 26-28 days old seventy-five males white Albino Mice, with an average body weight of $31.57 \pm 1.42 \mathrm{~g}$, were used. The mice were randomly assigned to five groups $(n=15)$ five animals per cage. The experiment was conducted for twenty-eight days and seven days of acclimatization under the same environmental conditions (room $\mathrm{T}^{\circ} 26 \pm 0.42^{\circ} \mathrm{C}$, and relative humidity 55 $\pm 5 \%$, and a $12 \mathrm{hr}$. light-dark cycle). Clean tape water and diets were provided ad libitum throughout the experiment.

\subsection{Experimental Procedures}

The experimental diets are shown in Table 1. The basal diets were developed, according to the recommendations of (Adeoti et al., 2018). The experimental diet of the two complementary diets were formulated from locally available foodstuffs using Nutrisurvey software (version, 2007) and processed by extrusion technology as reported by ((Shewangzaw et al., 2021). Finally, each group of experimental animals was assigned to each experimental diet. 
Table 1

Experimental Diet Formulation and Preparation

\begin{tabular}{|lllll|}
\hline Diets & Protein content \% & Wt. of Basal Diet $(\mathbf{g})$ & Wt. of Food $(\mathbf{g})$ & Total $(\mathbf{g})$ \\
\hline Diet 1 & 99 & 898.99 & 101.01 & 1000 \\
\hline Diet 2 & 12.56 & 203.82 & 796.18 & 1000 \\
\hline Diet 3 & 11.75 & 148.94 & 851.06 & 1000 \\
\hline Diet 4 & 10.78 & 72.36 & 927.64 & 1000 \\
\hline Diet 5 & 1000 & & 1000 \\
\hline
\end{tabular}

Were Diet 1- Casein diet; Diet 2- soybean (14\%), teff (29\%), and maize (57\%); Diet 3- bee larvae (13\%), teff (29\%), and maize (58\%) ; Diet 4- Commercial wean mix (enriched mama's choice); Diet 5- Basal diet alone ( $610 \mathrm{~g} / \mathrm{kg}$ corn starch, $50 \mathrm{~g} / \mathrm{kg}$ wheat bran, $100 \mathrm{~g} / \mathrm{kg}$ vegetable oil, $50 \mathrm{~g} / \mathrm{kg}$ mineral, and vitamin premix, $60 \mathrm{~g} / 100 \mathrm{~kg}$ glucose, $88 \mathrm{~g} / \mathrm{kg}$ sucrose, $20 \mathrm{~g} / \mathrm{kg}$ oyster shell, $2 \mathrm{~g} / \mathrm{kg} \mathrm{NaCl}$, and $20 \mathrm{~g} / 100 \mathrm{~kg}$ bone meal)

\subsection{Blood Sample Collection and Analysis}

Fasted blood serum was used for the determination of biochemical lipid profiles of TC, TG, HDL-C, and LDL-C. Animals were fasted for 12 hours prior to blood sample processing. Whole blood samples were collected from cardiac puncture mice (Hoff, 2000), using a 25 gauge needle and syringe anesthetized with xylazine and ketamine (Parasuraman et al., 2017; Santos Ed Wilson et al., 2016). The collected blood samples were immediately collected into the heparin-coated tubes of serum containers and placed on wet ice for further lipids analyses (Pierre et al., 2011). Sera was isolated from the whole blood, centrifuged at $3000 \mathrm{rpm}$ for $10 \mathrm{~min}$ at $4^{\circ} \mathrm{C}$ digital laboratory centrifuge (TD4C dc brushless motor centrifuge, Hunan, China).

\subsubsection{Lipids Profile Analysis}

Briefly, $50-\mu \mathrm{L}$ blood was aspired into a needle for the biochemical test, divided, and distributed for sample analysis to the chambers (Mazzaccara et al., 2008). Lipid profiles of TC, TG, HDL-C and LDL-C evaluations were done using automated pentra C400 made in France.

\subsubsection{Atherogenic and Castelli's Risk Indices}

Finally, atherogenic indices - Castelli's risk indices $(C R I-I)=T C / H D L-C,(C R I-I I)=L D L-C / H D L-C$, Atherogenic Coefficient $(A C)=(T C-H D L-C) / H D L-C$, Atherogenic Indices of Plasma $(A I P)=\log (T G / H D L-C)$ was calculated (Akangbou et al., 2018; Ikewuchi, 2009; Olamoyegun et al., 2016).

\subsection{Statistical Analysis}

Data on lipid profiles of TC, TG, HDL-C, and LDL-C, and atherogenic and Castelli's risk indices were presented as means and standard deviations. Person correlation between Atherogenic Indices and lipid profiles was calculated. Data were analyzed using SPSS for windows version, 23.0. The data obtained 
were subjected to one-way analysis of variance and Tukey's Honest Significant Difference test was used to examine the similarities among all experimental groups. The level of significant difference in P-Value $(P<0.05)$ was considered.

\section{Results}

\subsection{Lipid Profile}

Results of the lipid profile $(\mathrm{mg} / \mathrm{dl})$ among experimental diets are indicated in Table 2. The lipid profiles of TC, TG, HDL-C, and LDL-C were statistically significantly different $(P<0.001)$ between experimental treatments. Mice intake of diet 4 had low records of TC $(112.52 \mathrm{mg} / \mathrm{dl}), \mathrm{TG}(97.83 \mathrm{mg} / \mathrm{dl})$, and HDL-C $(47.87 \mathrm{mg} / \mathrm{dl})$. Also, mice assigned to diet 5 had high records of serum TG, LDL-C, and low HDL-C, which were 153,102 , and $50.12 \mathrm{mg} / \mathrm{dl}$, respectively. Mice intake of bee larvae containing CF (diet 3 ) had high (P $<0.001)$ records of TG $(167.79 \mathrm{mg} / \mathrm{dl})$ and HDL-C $(67.18 \mathrm{mg} / \mathrm{dl})$, and low in LDL-C $(71.73 \mathrm{mg} / \mathrm{dl})$ as compared to the other treatments. The increase in plasma HDL-C is considered to reduce the risk of coronary heart disease.

Among the experimental groups, Diet 2, Diet 3, and Diet 5 had high TC $(\mathrm{mg} / \mathrm{dl})$ in the blood, which was $131.23,123.34$, and 121.06, respectively. However, based on the present findings, it is difficult to be very certain that the diets caused CVDs. Therefore, further atherogenic indices should be calculated to identify a predictive indicator of coronary artery diseases.

Table 2

Comparison of serum lipid profile $(\mathrm{mg} / \mathrm{dl})$ of experimental Diets.

\begin{tabular}{|lllllll|}
\hline $\begin{array}{l}\text { Lipid } \\
\text { profile }\end{array}$ & Diet 1 & Diet 2 & Diet 3 & Diet 4 & Diet 5 & $\begin{array}{l}\text { P- } \\
\text { Value }\end{array}$ \\
\hline TC & $113.07 \pm$ & $131.23 \pm$ & $123.34 \pm$ & $112.52 \pm$ & $121.06 \pm$ & $<$ \\
& $4.13^{\mathrm{b}}$ & $1.19^{\mathrm{a}}$ & $2.23^{\mathrm{a}}$ & $5.25^{\mathrm{b}}$ & $1.77^{\mathrm{a}}$ & 0.001 \\
\hline TG & $141.25 \pm$ & $123.04 \pm$ & $167.79 \pm$ & $97.83 \pm$ & $153.96 \pm$ & $<$ \\
& $0.79^{\mathrm{c}}$ & $2.23^{\mathrm{d}}$ & $3.85^{\mathrm{a}}$ & $1.06^{\mathrm{e}}$ & $1.52^{\mathrm{b}}$ & 0.001 \\
\hline HDL-C & $59.53 \pm$ & $59.28 \pm$ & $67.18 \pm$ & $47.87 \pm$ & $50.12 \pm$ & $<$ \\
& $2.63^{\mathrm{b}}$ & $0.85^{\mathrm{b}}$ & $0.67^{\mathrm{a}}$ & $2.15^{\mathrm{c}}$ & $1.15^{\mathrm{c}}$ & 0.001 \\
\hline LDL-C & $86.66 \pm$ & $92.12 \pm$ & $71.73 \pm$ & $94.74 \pm$ & $102.30 \pm$ & $<$ \\
& $2.11^{\mathrm{c}}$ & $1.09^{\mathrm{b}}$ & $0.60^{\mathrm{d}}$ & $1.40^{\mathrm{b}}$ & $2.12^{\mathrm{a}}$ & 0.001 \\
\hline
\end{tabular}

The results are presented as SD of the means. means with different superscripts (alphabets) in the same row are significantly different $(P<0.05)$; Diet $1=$ Casein diet + Basal diet; Diet $2=$ maize, teff with soybean + Basal diet; Diet $3=$ maize, teff with bee larvae + Basal diet; Diet $4=$ commercial wean mix (enriched mama's choice) + Basal diet; Diet 5 = Basal diet alone; TC: Total Cholesterol; TG: Triglyceride; HDL-C: HighDensity Lipoprotein Cholesterol; LDL-C: Low-Density Lipoprotein Cholesterol 


\subsubsection{Atherogenic and Castelli's Risk Indices}

Results of AIP, CRI-I, CRI-II, and AC were found to be a statistically significant difference $(P<0.001)$ between experimental diets (Table 3). The high AIP, CRI-I, CRI-II, and AC were recorded on Diet 5, which was $0.49,2.50,2.04$, and 1.50, respectively. Also, Diet 4 was recorded high CRI-I (2.35), CRI-II (1.98), and AC (1.35). However, Diet 3 i.e the bee larvae containing had a low recoded of CRI-I (1.84), CRI-II (1.07), and $\mathrm{AC}(0.84)$.

Table 3

Distribution of Atherogenic Indices of Plasma, Castelli's Risk Indices, and Atherogenic Coefficient Among Experimental Treatments.

\begin{tabular}{|c|c|c|c|c|c|c|}
\hline Indices & Diet 1 & Diet 2 & Diet 3 & Diet 4 & Diet 5 & P-Value \\
\hline AIP & $0.38 \pm 0.03^{b}$ & $0.32 \pm 0.01^{c}$ & $0.40 \pm 0.01^{b}$ & $0.31 \pm 0.02^{c}$ & $0.49 \pm 0.01^{a}$ & 0.000 \\
\hline \multicolumn{7}{|l|}{ CRI } \\
\hline I & $1.90 \pm 0.08^{c}$ & $2.21 \pm 0.04^{b}$ & $1.84 \pm 0.04^{c}$ & $2.35 \pm 0.04^{a b}$ & $2.50 \pm 0.08^{a}$ & 0.000 \\
\hline II & $1.46 \pm 0.08^{b}$ & $1.55 \pm 0.02^{b}$ & $1.07 \pm 0.00^{c}$ & $1.98 \pm 0.12^{a}$ & $2.04 \pm 0.04^{a}$ & 0.000 \\
\hline $\mathrm{AC}$ & $0.90 \pm 0.08^{c}$ & $1.21 \pm 0.04^{b}$ & $0.84 \pm 0.04^{c}$ & $1.35 \pm 0.04^{\mathrm{ab}}$ & $1.50 \pm 0.08^{a}$ & 0.000 \\
\hline \multicolumn{7}{|c|}{$\begin{array}{l}\text { The results are presented as SD of the means. means with different superscripts (alphabets) in the } \\
\text { same row are significantly different }(P<0.05) \text {; Diet } 1=\text { Casein diet }+ \text { Basal diet; Diet } 2=\text { maize, teff } \\
\text { with soybean + Basal diet; Diet } 3=\text { maize, teff with bee larvae }+ \text { Basal diet; Diet } 4=\text { commercial wean } \\
\text { mix (enriched mama's choice) + Basal diet; Diet } 5=\text { Basal diet alone; AIP = Atherogenic Indices of } \\
\text { Plasma; CRI = Castelli's Risk Indices; AC = Atherogenic Coefficient }\end{array}$} \\
\hline
\end{tabular}

Table 3

The distribution of Atherogenic Indices of Plasma, Castelli's Risk Indices, and Atherogenic Coefficient Among the Experimental Treatments.

\begin{tabular}{|c|c|c|c|c|c|c|}
\hline Indices & Diet 1 & Diet 2 & Diet 3 & Diet 4 & Diet 5 & P-Value \\
\hline AIP & $0.38 \pm 0.03^{b}$ & $0.32 \pm 0.01^{c}$ & $0.40 \pm 0.01^{b}$ & $0.31 \pm 0.02^{c}$ & $0.49 \pm 0.01^{a}$ & 0.000 \\
\hline \multicolumn{7}{|l|}{ CRI } \\
\hline I & $1.90 \pm 0.08^{c}$ & $2.21 \pm 0.04^{b}$ & $1.84 \pm 0.04^{c}$ & $2.35 \pm 0.04^{a b}$ & $2.50 \pm 0.08^{a}$ & 0.000 \\
\hline II & $1.46 \pm 0.08^{b}$ & $1.55 \pm 0.02^{b}$ & $1.07 \pm 0.00^{c}$ & $1.98 \pm 0.12^{a}$ & $2.04 \pm 0.04^{a}$ & 0.000 \\
\hline$A C$ & $0.90 \pm 0.08^{c}$ & $1.21 \pm 0.04^{b}$ & $0.84 \pm 0.04^{c}$ & $1.35 \pm 0.04^{a b}$ & $1.50 \pm 0.08^{a}$ & 0.000 \\
\hline \multicolumn{7}{|c|}{$\begin{array}{l}\text { The results are presented as SD of the means. means with different superscripts (alphabets) in the } \\
\text { same row are significantly different }(P<0.05) \text {; Diet } 1=\text { Casein diet }+ \text { Basal diet; Diet } 2=\text { maize, teff } \\
\text { with soybean + Basal diet; Diet } 3=\text { maize, teff with bee larvae + Basal diet; Diet } 4=\text { commercial wean } \\
\text { mix (enriched mama's choice) + Basal diet; Diet } 5=\text { Basal diet alone; AIP = Atherogenic Indices of } \\
\text { Plasma; CRI = Castelli's Risk Indices; AC = Atherogenic Coefficient }\end{array}$} \\
\hline
\end{tabular}




\subsubsection{Person Correlation Between Atherogenic Indices and Risk Factors}

Results of correlation between Atherogenic indices of AIP, CRI-I, CRI-II, and AC and risk factors of TC, TG, HDL-C, and LDL-C are illustrated in Table 4. Results showed that there was a positive correlation of AIP with TC $(P=0.68 ; r=0.115)$ and LDL-C $(P=0.59 ; r=0.151)$, and a significant positive correlation with TG $(P=0.00 ; r=0.737)$. However, AIP was inversely correlated $(P=0.73 ; r=-0.096)$ with HDL-C. AIP was a positive correlation with TC, TG, and LDL-C and a negative correlation with HDL-C cholesterol. TC had no significant difference $(P>0.05)$ but, a positive correlation between AIP $(r=0.115), C R I-I$ and AC $(r=0.161)$, and negatively correlation with CRI-II $(r=-0.190)$. However, plasma TG had a negative association $(P>$ $0.05 ; r=-0.429)$ between indices of CRI-I and AC. Similarly, HDL-C level showed a significant difference ( $P$ $<0.001)$ and was negatively correlated between CRI-I ( $r=-0.872)$, CRI-II $(r=-0.971)$, and AC $(r=-0.872)$.

However, LDL-C levels showed a significant $(P<0.001)$ positive correlation between CRI-I $(r=0.875)$, CRIIII $(r=0.931)$, and $A C(r=0.875)$. Correlation of individual atherogenicity indices showed significant positive associations $(P<0.001)$ with one another; CRI-I vs CRI-II $(r=0.919)$, CRI-I vs AC $(r=1)$, CRI-II vs AC $(r=$ 0.919). Though, indices of AIP were not statistically significantly correlated but, positively correlated with CRIII $(P=0.47 ; r=0.204)$, CRI-II $(P=0.57 ; r=0.16)$, and AC $(P=0.47 ; r=0.204)$, respectively.

Table 4

Person Correlation between Atherogenic Indices and Lipid Profiles of experimental treatments.

\begin{tabular}{|c|c|c|c|c|c|c|c|c|}
\hline \multirow[t]{2}{*}{ Parameters } & \multicolumn{2}{|l|}{ AIP } & \multicolumn{2}{|l|}{ CRII } & \multicolumn{2}{|l|}{ CRI-II } & \multicolumn{2}{|l|}{$A C$} \\
\hline & $\mathbf{r}$ & $p$-Value & $r$ & $p$-Value & $\mathbf{r}$ & $p$-Value & $r$ & $p$-Value \\
\hline $\mathrm{TC}$ & 0.115 & 0.68 & 0.161 & 0.57 & -0.190 & 0.50 & 0.161 & 0.57 \\
\hline TG & 0.737 & $0.002^{\star *}$ & -0.429 & 0.11 & -0.535 & $0.04^{*}$ & -0.429 & 0.08 \\
\hline HDL-C & -0.096 & 0.73 & -0.872 & $0.00 * *$ & -0.971 & 0.00 ** & -0.872 & $0.00 * *$ \\
\hline LDL-C & 0.151 & 0.59 & 0.875 & $0.00 * *$ & 0.931 & $0.00 * *$ & 0.875 & $0.00 * \star$ \\
\hline AIP & - & 1 & 0.204 & 0.47 & 0.160 & 0.57 & 0.204 & 0.47 \\
\hline CRI-I & 0.204 & 0.47 & - & 1 & 0.919 & $0.00 * *$ & 1 & 0.00 ** \\
\hline CRIIII & 0.160 & 0.57 & 0.919 & $0.00 * *$ & - & 1 & 0.919 & $0.00 * *$ \\
\hline$A C$ & 0.204 & 0.47 & 1 & $0.00 * *$ & 0.919 & $0.00^{\star *}$ & - & 1 \\
\hline \multicolumn{9}{|c|}{$\begin{array}{l}\text { TC: Total cholesterol; TG: Triglyceride; HDL-C: High-Density Lipoprotein Cholesterol; LDL-C: Low- } \\
\text { Density Lipoprotein Cholesterol; AIP: Atherogenic indices of plasma; CRI: Castelli邓s Risk Indices; AC: } \\
\text { Atherogenic Coefficient }{ }^{*}=\text { Correlation is significant at the } 0.05 \text { level; ** Correlation is significant at the } \\
0.01 \text { level }\end{array}$} \\
\hline
\end{tabular}

\section{Discussions}


Nutrient consumption in infancy influences lipid profile (Thorsdottir et al., 2003). The diet of high lipids causes hyperlipidemia, which was marked by an increase in TC, TG, LDL-C, and a decrease in HDL-C (Sa'adah et al., 2017), and was the key factor in CVD progression (Kazemi et al., 2018). Additionally, according to the reports of (Chandrashekhar et al., 2020), LDL-C was proatherogenic and oxidation of LDL-C within the arterial wall would be an important early step in atherogenesis. Serum cholesterol (and hence LDL-C) has constantly been shown to be a significant risk factor for CHD and other major CVD as well.

According to the findings of (Haber et al., 2019), honey bees had an increased amount of palmitic and oleic acid, which was the dominant fatty acid determined in the larvae. Therefore, diets richer in palmitic and oleic acid like diet 3 increase the HDL-C levels and decrease LDL-C or lower the ratio of LDL-C to HDLC (CRI-II) (Cook et al., 1997; Ng et al., 1992; Tinahones et al., 2004). Also, this Monounsaturated Fatty Acids (MUFA) omega-9 fatty acid is important in the human diet; it has been proven effective to reduce LDL and TC levels (Mattson \& Grundy, 1985). High HDL-C protects the body by boosting reverse cholesterol transport by scavenging excessive cholesterol from peripheral tissues, which is then esterified with the aid of lecithin: cholesterol acyltransferase and transports to the liver and steroidogenic organs for the synthesis of bile acids and lipoproteins and ultimate removal from the body (Ademuyiwa et al., 2005; Ikewuchi, 2009).

LDL-C was shown to be the primary cause of the link between elevated cholesterol and an increased risk of heart disease. HDL-C, on the other hand, has been inversely related to the risk of death from coronary heart disease (Kannel et al., 1979). So, the "cholesterol hypothesis" was born because of these studies, which hypothesized that LDL-C is responsible for the progression of atherosclerosis and that reducing LDL-C would lower the risk of myocardial infarction and other cardiovascular events. (Soppert et al., 2020). Therefore, the present study showed that diet 3 had recorded low LDL-C and high HDL-C, and low records of CRI-I, CRI-II, and AC. The correlation of HDL-C with other indices was in line with the report of (Afshinnia \& Pennathur, 2020) a strong inverse relationship between HDL-C levels and risk of CVD.

The elevation of serum TC, TG, and LDL-C has been implicated as a principal risk factor for atherosclerotic CVD (Erukainure et al., 2011). In this study diet 5 had a high record of LDL-C, and therefore the probability of causing CVD would be highest than the other diets. Therefore, to reduce the risk of CVD, current recommendations focus on lowering LDL-C by reducing the intake of saturated fat (Siri-Tarino \& Krauss, 2016). The lower plasma HDL-C has indicated the risk of CVD (Ikewuchi, 2009; Martirosyan et al., 2007). From the results perspective, the lower concentration of LDL-C in diet 3 would be associated with the inclusion of bee larvae in the developed foods, which had high in MUFAs, and enrichment of the diet with MUFA lowers LDL-C (Ghosh et al., 2016; Kris-Etherton, 1999). From the findings, isolated elevation in TG (diet 3) increases CVD risk; however, according to the report of (Stensvold et al., 1993), these effects can be balanced by cardioprotective lipoprotein of HDL-C. The finding has supported a study by (King, 2012) that reported high levels of HDL-C that was associated with reduced cardiovascular risk. 
A high-fat diet's significant influence on serum lipids, (Holman, 1961), has been related to metabolic and CVD (dos Santos Lacerda et al., 2018). Also, serum lipid levels, especially serum cholesterol were a major risk factor for atherosclerosis and CVDs that significantly contributes to mortality (Harit et al., 2008). Also, Mott and colleagues (Mott et al., 1991) reported elevated atherosclerotic lesions that were associated with elevated plasma TC levels, and these were related to increased cholesterol levels in children's diets. So, a decrease in serum lipids leads to the good functioning of the heart muscle (Amara. et al., 2020). According to the report of (Billingsley \& Carbone, (2018), a lower intake of PUFAs and a higher intake of dietary cholesterol and saturated fats raise blood total cholesterol levels.

From the results of blood lipid profiles, it was difficult to conclude which experimental diet had a cardioprotective potential and prevents infants or children from CVD. In addition to routine lipid investigations, the inclusion of atherogenic indices was a better index for screening for early detection of atherogenic CVD (Sasikala \& Goswami, 2020). Furthermore, if other atherogenic risk parameters tend to be normal, atherogenic indices would be a viable diagnostic option (U. I. Nwagha \& Igwe, 2005).

Therefore, the lipid profile assay has found a useful application in the assessment of malnourished children (Kimak et al., 2000; Taskinen, 2000). AIP (Niroumand et al., 2015; Ranjit et al., 2015; Sasikala \& Goswami, 2020) and AC (Dobias ova, 2004) were also useful diagnostic tools to predict the risk of atherosclerosis and coronary heart disease the higher the value, the higher the risk of developing CVD and vice versa.

During atherogenesis, lipids accumulate in the vascular wall and trigger inflammatory reactions that stimulate atherosclerosis progression (Weber \& Noels, 2011). However, the results of the mice assigned on both Diet 4 and 5 would be the prediction of cardiovascular events (Edwards et al., 2017). Also, CRI-II presented more prognostic value compared with ordinary LDL-C or HDL-C fractions (Sasikala \& Goswami, 2020). Thus, this finding agreed with the study of (Bo et al., 2018; Niroumand et al., 2015). Results of TC and any indices of atherogenicity were agreed with the report of (Kamoru et al., 2017), and a statistically significant association was observed.

\section{Conclusions}

Results of the present study revealed that the use of atherogenic indices is an indicator to confirm either the diets are potentially causing or be associated with CVD or not as compared to the traditional lipid profile. The results of atherogenic indices: TC/HDL-C, LDL-C/HDL-C, and (TC-HDL-C)/ HDL-C showed that intake of bee larvae-based complementary foods could be used to prevent the risk of atherosclerotic cardiovascular disease. However, further research on fatty acids profiles of the diets, diets on histopathology changes on mice, and intake of developed complementary foods on physiological and biological effects on infants and young children should be conducted.

\section{Abbreviations}




\begin{tabular}{ll} 
AC & Atherogenic Coefficient \\
\hline AIP & Atherogenic Indices of Plasma \\
\hline CHD & Coronary Heart Disease \\
\hline CRI-I & Castelli's Risk Indices-I \\
\hline CRI-II & Castelli's Risk Indices-II \\
\hline CVD & Cardiovascular Disease \\
\hline HDL-C & High-Density Lipoproteins Cholesterol \\
\hline LDL-C & Low-Density Lipoproteins Cholesterol \\
\hline MUFAs & Monounsaturated Fatty Acids \\
\hline PUFAs & Polyunsaturated Fatty Acids \\
\hline SFAs & Saturated Fatty Acids \\
\hline SPSS & Statistical Package For Social Science \\
\hline TC & Total Cholesterol \\
\hline TG & Triglyceride
\end{tabular}

\section{Declarations}

Ethics approval and consent to participate

All experimental procedures were approved by the Research Ethics Committee of the College of Veterinary Medicine and Animal Sciences, University of Gondar, Ethiopia.

\section{Consent for publication}

Not applicable

\section{Availability of data and materials}

The datasets used and/or analysed during the current study are available from the corresponding author on reasonable request.

\section{Competing interests}

The authors declare that they have no competing interests.

\section{Funding}


This research was funded by DAAD/RUFORUM, In-Country/In-Region Scholarship Programme-Regional Universities Forum for Capacity Building in Agriculture 2018, Germany grant number [57429563].

\section{Authors' contributions}

Conceptualization, S.A.M.; methodology, S.A.M., J.K., B.K., and M.W; software, S.A.M.; validation, S.A.M., J.K., B.K., and M.W.; formal analysis, S.A.M.; investigation, S.A.M.; resources, S.A.M.; data curation, S.A.M.; writing-original draft preparation, S.A.M.; writing-review and editing, S.A.M., J.K., B.K., and M.W.; visualization, S.A.M.; supervision, J.K., B.K., and M.W.; project administration, S.A.M.; funding acquisition, S.A.M. All authors have read and agreed to the published version of the manuscript.

\section{Acknowledgments}

The authors would like to give special thanks to the German Academic Exchange Service (DAAD) for the sponsorship of this research work. We are also grateful to Jomo Kenyatta University of Agriculture and Technology, Kenya, and the University of Gondar, Ethiopia, for this research laboratory work.

\section{References}

Ademuyiwa O, Ugbaja RN, Idumebor F, Adebawo O. Plasma lipid profiles and risk of cardiovascular disease in occupational lead exposure in Abeokuta, Nigeria. Lipids in Health Disease. 2005;4(1):1-7. doi:https://doi.org/10.1186/1476-511X-4-19.

Adeoti OA, Osundahunsi Oluwatooyin F, A SA. (2018). Protein Quality, Haematological and Histopathological Studies of Rats Fed with Maize-based Complementary Diet Enriched with Fermented and Germinated Moringa Oleifera Seed Flour. Nutrition Food Science International Journal, 7(1). doi:10.19080/NFSIJ.2018.07.555705.

Afrifa J, Botchway FA, Opoku YK, Badohu J, Ocran HE, Asare KK, Essien-Baidoo S. Assessment of cardiovascular risk in post-menopausal women in Ghana. F1000Research. 2019;8(845):845. doi:https://doi.org/10.12688/f1000research.19447.1.

Afshinnia F, Pennathur S. Lipids and Cardiovascular Risk with CKD. Clin J Am Soc Nephrol. 2020;15(1):57. doi:10.2215/cjn.13531119.

Akangbou PC, Chuemere AN, llochi O. Impairment of cardiovascular function indices in male rats induced by aluminium-tainted water: Atherogenic indices and predictor ratio assessment. Discovery. 2018;54(275):442-6.

Al Shawaf E, Al-Ozairi E, Al-Asfar F, Mohammad A, Al-Beloushi S, Devarajan S,... Arefanian H. (2020). Atherogenic Index of Plasma (AIP) a Tool to Assess Changes in Cardiovascular Disease Risk Post Laparoscopic Sleeve Gastrectomy. Journal of Diabetes Research, 2020, 2091341.

doi:10.1155/2020/2091341. 
Amara., Koffi A, Goze BN, Bleyere MN, Yapo PA, Medicines. Moringa oleifera Diets Effect on Haematological Parameters of Rat (Ratus norvegicus). J Biosci. 2020;8(05):20.

doi:10.4236/jbm.2020.85003.

Berciano S, Ordovás JM. Nutrition and Cardiovascular Health. Revista Española de Cardiología (English Edition). 2014;67(9):738-47. doi:https://doi.org/10.1016/j.rec.2014.05.003.

Bo MS, Cheah WL, Lwin S, Moe Nwe T, Win TT, Aung M. (2018). Understanding the Relationship between Atherogenic Index of Plasma and Cardiovascular Disease Risk Factors among Staff of an University in Malaysia. Journal of Nutrition and Metabolism, 2018, 7027624. doi:10.1155/2018/7027624.

Briggs MA, Petersen KS, Kris-Etherton PM. (2017). Saturated Fatty Acids and Cardiovascular Disease: Replacements for Saturated Fat to Reduce Cardiovascular Risk. Healthcare (Basel), 5(2). doi:10.3390/healthcare5020029.

Casas R, Castro-Barquero S, Estruch R, Sacanella E. Nutrition and cardiovascular health. Int J Mol Sci. 2018;19(12):3988. doi:https://doi.org/10.3390/ijms19123988.

Castelli WP, Abbott RD, McNamara PM. Summary estimates of cholesterol used to predict coronary heart disease. Circulation. 1983;67(4):730-4.

Chambers L. Complementary feeding: vegetables first, frequently and in variety. In: Wiley Online Library; 2016.

Chandrashekhar D, Anandkumar M, Babu P. Impact of Obesity on Castelli's Risk Index I and II, in Young Adult Females. International Journal of Physiology. 2020;8(1):21-6.

Chane T, Bitew S, Mekonnen T, Fekadu W. Initiation of complementary feeding and associated factors among children of age 6-23 months in Sodo town, Southern Ethiopia: Cross-sectional study. Pediatric reports. 2018;9(4):7240-0. doi:10.4081/pr.2017.7240.

Cook S, Konrad S, Goh Y, French M, Clandinin M. Palmitic acid effect on lipoprotein profiles and endogenous cholesterol synthesis or clearance in humans. Asia Pac J Clin Nutr. 1997;6:6-11.

Dobias `ova M. Atherogenic index of plasma [log (triglycerides/HDL-cholesterol)]: theoretical and practical implications. Clin Chem. 2004;50(71):1113-5.

doi:https://doi.org/10.1373/clinchem.2004.033175.

dos Santos Lacerda D, Garbin de Almeida M, Teixeira C, De Jesus A, Da Silva Pereira Júnior É, Bock M, Funchal P, C. Biochemical and physiological parameters in rats fed with high-fat diet: the protective effect of chronic treatment with purple grape juice (bordo variety). Beverages. 2018;4(4):100. doi:http://dx.doi.org/10.3390/beverages 4040100 . 
Edwards MK, Blaha MJ, Loprinzi PD. (2017). Atherogenic index of plasma and triglyceride/high-density lipoprotein cholesterol ratio predict mortality risk better than individual cholesterol risk factors, among an older adult population. Paper presented at the Mayo Clinic Proceedings.

Erukainure OL, Abovwe JA, Adefegha AS, Egwuche RU, Fafunso MA. Antilipemic and hypocholesteremic activities of Globimetula braunii in rats. Experimental toxicologic pathology. 2011;63(7-8):657-61. doi:https://doi.org/10.1016/j.etp.2010.05.007.

Finke MD. Nutrient composition of bee brood and its potential as human food. Ecology of food nutrition. 2005;44(4):257-70. doi:http://dx.doi.org/10.1080/03670240500187278.

Ghosh S, Jung C, Meyer-Rochow VB. Nutritional value and chemical composition of larvae, pupae, and adults of worker honey bee, Apis mellifera ligustica as a sustainable food source. Journal of Asia-Pacific Entomology. 2016;19(2):487-95. doi:https://doi.org/10.1016/j.aspen.2016.03.008.

Haber M, Mishyna M, Martinez JI, Benjamin O. Edible larvae and pupae of honey bee (Apis mellifera): Odor and nutritional characterization as a function of diet. Food Chem. 2019;292:197-203. doi:https://doi.org/10.1016/j.foodchem.2019.04.041.

Harit D, Faridi MMA, Aggarwal A, Sharma SB. Lipid profile of term infants on exclusive breastfeeding and mixed feeding: a comparative study. Eur J Clin Nutr. 2008;62(2):203-9. doi:10.1038/sj.ejcn.1602692.

Hoff J. (2000). Methods of blood collection in the mouse. Technique, 29(10).

Holman RL. Atherosclerosis-a pediatric nutrition problem? Am J Clin Nutr. 1961;9(5):565-9. doi:https://doi.org/10.1093/ajcn/9.5.565.

Ikewuchi C. (2009). Alteration of plasma lipid profiles and atherogenic indices by Stachytarpheta jamaicensis L.(Vahl). Biokemistri, 21(2).

Kamoru AA, Japhet OM, Adetunji AD, Musa MA, Hammed OO, Akinlawon AA,.. . Roji SM. (2017). Castelli risk index, atherogenic index of plasma, and atherogenic coefficient: emerging risk predictors of cardiovascular disease in hiv-treated patients. Saudi Journal of Medical and Pharmaceutical Sciences, 1101-1110.

Kannel WB, Castelli WP, Gordon T. Cholesterol in the prediction of atherosclerotic disease: new perspectives based on the Framingham study. Annals of internal Medicine. 1979;90(1):85-91.

Kanthe PS, Patil BS, Bagali S, Shaikh GB, Aithala M. Atherogenic index as a predictor of cardiovascular risk among women with different grades of obesity. International Journal of Collaborative Research on Internal Medicine Public Health. 2012;4(10):0-0.

Kazemi T, Hajihosseini M, Moossavi M, Hemmati M, Ziaee M. Cardiovascular Risk Factors and Atherogenic Indices in an Iranian Population: Birjand East of Iran. Clinical Medicine Insights Cardiology. 
Kimak E, Solski J, Janicka L. Lipoprotein profiles at different stages of chronic renal insufficiency. Ren Fail. 2000;22(1):63-71. doi:https://doi.org/10.1081/JDI-100100852.

King A. Cardioprotective effects of HDL cholesterol called into question. Nature Reviews Cardiology. 2012;9(7):374-4. doi:https://doi.org/10.1038/nrcardio.2012.80.

Kris-Etherton PM. Monounsaturated fatty acids and risk of cardiovascular disease. Circulation. 1999;100(11):1253-8. doi:https://doi.org/10.1161/01.CIR.100.11.1253.

Kuller LH. Nutrition, Lipids, and Cardiovascular Disease. Nutr Rev. 2006;64(suppl_1):15-26. doi:10.1111/j.1753-4887.2006.tb00230.x.

Lacroix S, Cantin J, Nigam A. Contemporary issues regarding nutrition in cardiovascular rehabilitation. Annals of physical rehabilitation medicine. 2017;60(1):36-42.

doi:https://doi.org/10.1016/j.rehab.2016.07.262.

Martirosyan DM, Miroshnichenko L, Zoloedov VI, Pogojeva A, Kulakova SN. Amaranth oil application for coronary heart diseases. Agro Food Industry Hi-Tech. 2007;18(3):44-5.

Mattson FH, Grundy SM. Comparison of effects of dietary saturated, monounsaturated, and polyunsaturated fatty acids on plasma lipids and lipoproteins in man. J Lipid Res. 1985;26(2):194-202. doi:https://doi.org/10.1016/S0022-2275(20)34389-3.

Mazzaccara C, Labruna G, Cito G, Scarfò M, De Felice M, Pastore L, Sacchetti L. Age-related reference intervals of the main biochemical and hematological parameters in C57BL/6J, 129SV/EV and C3H/HeJ mouse strains. PloS one. 2008;3(11):e3772. doi:https://doi.org/10.1371/journal.pone.0003772.

Mehta D, Malik AB. Signaling Mechanisms Regulating Endothelial Permeability. Physiol Rev. 2006;86(1):279-367. doi:10.1152/physrev.00012.2005.

Mensink RP. Effects of stearic acid on plasma lipid and lipoproteins in humans. Lipids. 2005;40(12):1201-5. doi:10.1007/s11745-005-1486-x.

Mott GE, Lewis DS, McGILL JR, H. C. Deferred effects of preweaning nutrition on lipid metabolism. Ann N Y Acad Sci. 1991;623(1):70-80. doi:https://doi.org/10.1111/j.1749-6632.1991.tb43719.x.

Mozaffarian D, Ludwig DS. Dietary guidelines in the 21 st century-a time for food. Jama. 2010;304(6):681-2. doi:10.1001/jama.2010.1116.

Ng TK, Hayes KC, DeWitt GF, Jegathesan M, Satgunasingam N, Ong AS, Tan D. Dietary palmitic and oleic acids exert similar effects on serum cholesterol and lipoprotein profiles in normocholesterolemic men and women. J Am Coll Nutr. 1992;11(4):383-90. doi:10.1080/07315724.1992.10718241. 
Niroumand S, Khajedaluee M, Khadem-Rezaiyan M, Abrishami M, Juya M, Khodaee G, Dadgarmoghaddam M. Atherogenic Index of Plasma (AIP): A marker of cardiovascular disease. Medical journal of the Islamic Republic of Iran. 2015;29:240.

Nwagha U, Ikekpeazu E, Ejezie F, Neboh E, Maduka I. (2010). Atherogenic index of plasma as useful predictor of cardiovascular risk among postmenopausal women in Enugu, Nigeria. Afr Health Sci, 10(3).

Nwagha Ul, Igwe J. Atherogenic Index of Plasma: A significant indicator for the onset of Atherosclerosis during menopause in hypertensive females of South East Nigeria. International Journal of Medicine Health Development. 2005;10(2):67-71.

Olamoyegun MA, Oluyombo R, Asaolu SO. Evaluation of dyslipidemia, lipid ratios, and atherogenic index as cardiovascular risk factors among semi-urban dwellers in Nigeria. Ann Afr Med. 2016;15(4):194-9. doi:10.4103/1596-3519.194280.

Parasuraman S, Raveendran R, Kesavan R. Blood sample collection in small laboratory animals. Journal of pharmacology pharmacotherapeutics. 2017;1(2):87-93. doi:10.4103/0976-500X.72350.

Pierre PJ, Sequeira MK, Corcoran CA, Blevins MW, Gee M, Laudenslager ML, Bennett A j. (2011). Hematological and serum biochemical indices in healthy bonnet macaques (Macaca radiata). Journal of medical primatology, 4O(5), 287-293. doi:https://doi.org/10.1111/j.1600-0684.2011.00466.x.

Prentice A, Williams A. The influence of maternal, fetal and child nutrition on the development of chronic disease in later life. The Stationery Office; 2011.

Przyrembel H. (2012). Timing of introduction of complementary food: short-and long-term health consequences. Annals of Nutrition Metabolism, 60 Suppl 2, 8-20.

doi:http://dx.doi.org/10.1159\%2F000336287.

Rached FH, Chapman MJ, Kontush A. An Overview of the New Frontiers in the Treatment of Atherogenic Dyslipidemias. Clin Pharmacol Ther. 2014;96(1):57-63. doi:https://doi.org/10.1038/clpt.2014.85.

Ranjit PM, Guntuku GS, Pothineni RB. New atherogenic indices: Assessment of cardio vascular risk in post menopausal dyslipidemia. Asian Journal of Medical Sciences. 2015;6(6):25-32. doi:https://doi.org/10.3126/ajms.v6i6.12209.

Sa'adah NN, Purwani KI, Nurhayati APD, Ashuri NM. (2017). Analysis of lipid profile and atherogenic index in hyperlipidemic rat (Rattus norvegicus Berkenhout, 1769) that given the methanolic extract of Parijoto (Medinilla speciosa). Paper presented at the AIP Conference Proceedings.

Santos Ed, Wilson, Oliveira DC, d., Hastreiter A, Silva GB, d., Beltran JSdO, Tsujita M,.. . Borelli P. Hematological and biochemical reference values for C57BL/6, Swiss Webster and BALB/c mice. Brazilian Journal of Veterinary Research Animal Science. 2016;53(2):138-45. doi:10.11606/issn.16784456.v53i2p138-145. 
Sasikala T, Goswami K. Castelli risk index-1 and atherogenic coefficient are better predictors of cardiometabolic risk in patients with hypothyroidism. International Journal of Clinical Biochemistry Research. 2020;7(2):254-9. doi:https://doi.org/10.18231/j.ijcbr.2020.055.

Sharifi-Rad J, Rodrigues CF, Sharopov F, Docea AO, Karaca C, Sharifi-Rad A, Calina M, D. Diet, Lifestyle and Cardiovascular Diseases: Linking Pathophysiology to Cardioprotective Effects of Natural Bioactive Compounds. International Journal of Environmental Research Public Health. 2020;17(7):2326. doi:https://doi.org/10.3390/ijerph17072326.

Shewangzaw, A. M., Kinyuru, J. N., Mokua, B. K., \& Tenagashaw, M. W. (2021). Nutritional Quality and Safety of Complementary Foods Developed from Blends of Staple Grains and Honey Bee Larvae (<i > Apis mellifera). International Journal of Food Science, 2021, 5581585. doi:10.1155/2021/5581585

Siri-Tarino PW, Krauss RM. Diet, lipids, and cardiovascular disease. Curr Opin Lipidol. 2016;27(4):323-8. doi:10.1097/mol.0000000000000310.

Soppert J, Lehrke M, Marx N, Jankowski J, Noels H. Lipoproteins and lipids in cardiovascular disease: from mechanistic insights to therapeutic targeting. Adv Drug Deliv Rev. 2020;159:4-33. doi:https://doi.org/10.1016/j.addr.2020.07.019.

Stensvold I, Tverdal A, Urdal P, Graff-Iversen S. Non-fasting serum triglyceride concentration and mortality from coronary heart disease and any cause in middle aged Norwegian women. British medical journal. 1993;307(6915):1318-22. doi:https://doi.org/10.1136/bmj.307.6915.1318.

Taskinen M. Skeletal muscle protein reserves in children with cancer: Nutritional and metabolic aspects from diagnosis to long-term follow-up. European Journal of Clinical Nutrition volume. 2000;54:219-24. doi:https://doi.org/10.1038/sj.ejcn.1600923.

Thorsdottir I, Gunnarsdottir I, Palsson GI. Birth weight, growth and feeding in infancy: relation to serum lipid concentration in 12-month-old infants. Eur J Clin Nutr. 2003;57(11):1479-85. doi:10.1038/sj.ejcn.1601714.

Tinahones FJ, Gómez-Zumaquero JM, Monzón A, Rojo-Martínez G, Pareja A, Morcillo S,.. . Soriguer F. Dietary palmitic acid influences LDL-mediated lymphocyte proliferation differently to other mono- and polyunsaturated fatty acids in rats. Diabetes Nutr Metab. 2004;17(5):250-8.

Uauy R, Castillo C. Lipid Requirements of Infants: Implications for Nutrient Composition of Fortified Complementary Foods. J Nutr. 2003;133(9):2962S-2972S. doi:10.1093/jn/133.9.2962S.

Vieira TCL, Trigo M, Alonso RR, Ribeiro RHC, Cardoso MRA, Cardoso ACA, Cardoso MAA. Avaliação do consumo alimentar de crianças de 0 a 24 meses com cardiopatia congênita. Arq Bras Cardiol. 2007;89:219-24. doi:https://doi.org/10.1590/S0066-782X2007001600002. 
Weber C, Noels H. Atherosclerosis: current pathogenesis and therapeutic options. Nature medicine. 2011;17(11):1410-22. doi:https://doi.org/10.1038/nm.2538.

WHO. (2018). Noncommunicable diseases country profiles 2018. Retrieved from https://apps.who.int/iris/bitstream/handle/10665/148114/9789241564854_eng.pdfaccessed on 12 December 2019.

Wu T-T, Gao Y, Zheng Y-Y, Ma Y-T, Xie X. Atherogenic index of plasma (AIP): a novel predictive indicator for the coronary artery disease in postmenopausal women. Lipids in Health Disease. 2018;17(1):197. doi:10.1186/s12944-018-0828-z. 